\title{
Rare diseases and mental health in the UK - a quantitative survey and multi-stakeholder workshop
}

\section{CURRENT STATUS: UNDER REVISION}

강 Orphanet Journal of Rare Disease $\triangle B M C$

Rosa Spencer-Tansley

Genetic Alliance UK

Nick Meade

Genetic Alliance UK

Farhana Ali

Genetic Alliance UK

Amy Simpson

Genetic Alliance UK

Amy Hunter

Genetic Alliance UK

amy@geneticalliance.org.ukCorresponding Author

ORCiD: https://orcid.org/0000-0001-5076-8761

\section{DOI:}

$10.21203 / \mathrm{rs} .2 .19070 / \mathrm{v} 1$

\section{SUBJECT AREAS}

Internal Medicine

\section{KEYWORDS}

rare disease, undiagnosed, mental health, health service, patient experience, survey, recommendations 
Abstract

Background: Rare disease patients and carers report significant impacts on mental health but this has not been extensively studied. We explored the experiences of UK-based individuals through an online survey, and offer recommendations for policy and practice developed with a multi-stakeholder workshop.

Results: In total 1,355 patients and 571 carers responded to the survey. Due to their rare condition, the majority of respondents had felt worried/anxious (95\%); stressed (93\%); low/depressed (90\%); emotionally exhausted (88\%). Thirty-six percent of patients and $19 \%$ of carers had had suicidal thoughts. Challenges that are particular to rare conditions and which negatively affect mental health included low knowledge of the condition amongst healthcare professionals (88\%), not being believed or taken seriously by healthcare professionals ( $80 \%)$, and lack of available information about the condition (76\%). Only $23 \%$ of respondents felt mental health was considered by healthcare professionals as equally important as physical health. Almost half of patients (46\%) and carers (48\%) reported never having been asked about their mental health, or that of the person they care for, by healthcare professionals. Forty-six percent of respondents had received professional psychological support; the most common reason for not having accessed professional psychological support was that it had not been suggested (41\%). Fifty-nine percent of respondents had accessed sources of additional emotional support, such as patient groups, with the majority (75\%) having found this support themselves. With input from our multi-stakeholder workshop we developed recommendations for healthcare professionals to be supported to effectively and sensitively recognise and address patients' and carers' mental health needs; and for service level coordination of care to integrate professional psychological support with rare disease services.

Conclusions: Living with a rare disease can substantially impact mental health. Many of the drivers of poor mental health reflect issues specific to managing rare conditions. To meet existing UK government commitments, there should be a focus on empowering healthcare professionals who treat rare disease patients and on integration of mental health support with rare disease services. Full-text 
Due to technical limitations, full-text HTML conversion of this manuscript could not be completed.

However, the manuscript can be downloaded and accessed as a PDF.

\section{Figures}

\begin{tabular}{|c|c|}
\hline $\begin{array}{l}\text { Literature } \\
\text { scoping }\end{array}$ & $\begin{array}{l}\text { - Reviewed published literature } \\
\text { - Put out a call for information from members of Genetic Alliance UK ( } 200+\text { patient } \\
\text { organisations) }\end{array}$ \\
\hline & $\begin{array}{l}\text { - Included rare disease patients and carers, clinicians, a representative from a national } \\
\text { mental health charity and a social science academic }\end{array}$ \\
\hline & -From National Social Care Research Ethics Committee \\
\hline & $\begin{array}{l}-8 \text { patients, } 8 \text { carers } \\
\text { - Semi-structured interviews } \\
\text { - Findings analysed using thematic analysis }\end{array}$ \\
\hline $\begin{array}{l}\text { Surv } \\
\text { develop }\end{array}$ & $\begin{array}{l}\text { - Discussed findings of literature scoping exercise and interviews with advisory group } \\
\text { - Identified relevant tools/questions from literature for use in survey } \\
\text {-Piloted survey with five individuals } \\
\text {-Discussed feedback with advisory group, agreed amendments made }\end{array}$ \\
\hline Survey is live & $\begin{array}{l}\text { - November - December } 2017 \\
\text {-1926 individuals responded; } 1885 \text { total respondents eligible to take part (1231 patients, } \\
564 \text { carers) } \\
\text {-Descriptive stastical analysis to analyse findings }\end{array}$ \\
\hline $\begin{array}{l}\text { Stakeholder } \\
\text { workshop }\end{array}$ & $\begin{array}{l}\text {-Included representatives from patient organisations and health professional } \\
\text { organisations/bodies, and individual clinicians, patients and carers } \\
\text {-Discussed project findings, including practice and service implications. }\end{array}$ \\
\hline
\end{tabular}

Figure 1

Flow chart of study methods 
